\title{
Solvent effect on the excited-state intramolecular double proton transfer of 1,3-bis(2-pyridylimino)-4,7-dihydroxyisoindole
}

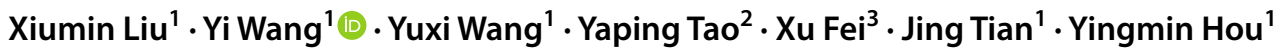 \\ Received: 11 July 2021 / Accepted: 16 August 2021 / Published online: 31 August 2021 \\ (c) The Author(s), under exclusive licence to European Photochemistry Association, European Society for Photobiology 2021
}

\begin{abstract}
Density functional theory (DFT) and time-dependent density functional theory (TDDFT) are used to study the solvatochromic effect and the excited-state intramolecular double proton transfer (ESIDPT) of 1,3-Bis(2-pyridylimino)-4,7-dihydroxyisoindole (BPI-OH) in different kinds of solvents. The hydrogen bonding parameters and IR spectra reveal that in the excited state, the strength of excited hydrogen bond increase with the decrease of solvent polarity. Furthermore, the reduction density gradient (RDG) analysis confirms the corresponding conclusion. Frontier molecular orbitals (FMOs) are analyzed, illuminating that the smaller the polarity of solvent, the smaller the energy gap between the HOMO and LUMO. The structures of BPI-OH (N) (normal), BPI-OH ( $\left.\mathrm{T}_{1}\right)$ (single), and BPI-OH $\left(\mathrm{T}_{2}\right)$ (double) were optimized. Previous reports found the double protons in BPI-OH molecule are transferred step-by-step process $\mathrm{BPI}-\mathrm{OH}(\mathrm{N}) \rightarrow \mathrm{BPI}-\mathrm{OH}\left(\mathrm{T}_{1}\right) \rightarrow \mathrm{BPI}-\mathrm{OH}\left(\mathrm{T}_{2}\right)$ in the ground state $\left(\mathrm{S}_{0}\right)$ and the first excited singlet state $\left(\mathrm{S}_{1}\right)$. Here, the potential energy curves of $\mathrm{O}_{1}-\mathrm{H}_{2}$ and $\mathrm{O}_{4}-\mathrm{H}_{5}$ in the $\mathrm{S}_{0}$ and $\mathrm{S}_{1}$ states were scanned in four kinds of solvents, respectively. It was found that in $\mathrm{S}_{1}$ state, $\mathrm{BPI}-\mathrm{OH}(\mathrm{N}) \rightarrow \mathrm{BPI}-\mathrm{OH}\left(\mathrm{T}_{1}\right)$ was more prone to proton transfer than BPI-OH $\left(\mathrm{T}_{1}\right) \rightarrow \mathrm{BPI}-\mathrm{OH}\left(\mathrm{T}_{2}\right)$. In addition, by comparing the reaction energy barriers of the four kinds of solvents, it can be found that ESIPT is difficult to occur with the increase of solvent polarity. Meanwhile, it was also studied that $\mathrm{MeOH}$ as an explicit solvent was more likely to promote the ESIPT process than other implicit solvents.
\end{abstract}

Yi Wang

wangyi@dlpu.edu.cn

$\triangle$ Yingmin Hou

yingminhou@163.com

1 School of Biological Engineering, Dalian Polytechnic University, Dalian 116034, People's Republic of China

2 College of Physics and Electronic Information, Luoyang Normal University, Luoyang 471022, People's Republic of China

3 Lab Analyst of Network Information Center, Dalian Polytechnic University, Dalian 116034, People's Republic of China 


\section{Graphic abstract}

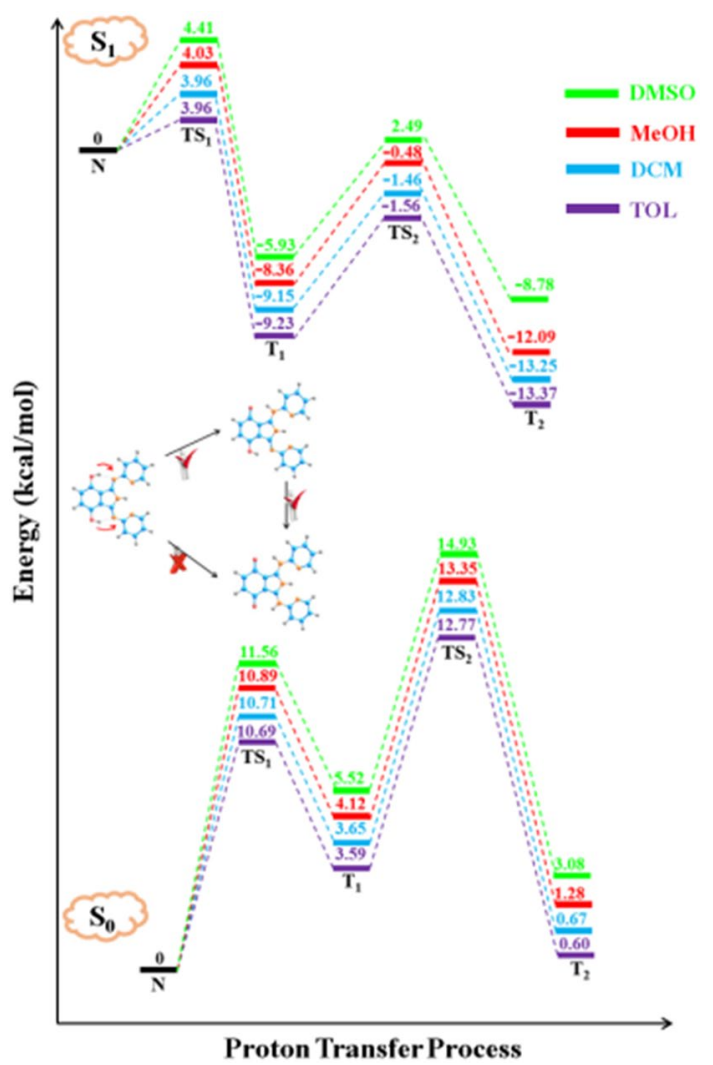

Keywords Excited-state intramolecular double proton transfer $\cdot$ Solvent polarity $\cdot$ Hydrogen bond $\cdot$ Stepwise proton transfer

\section{Introduction}

Hydrogen bond is a common secondary bond in nature [1, 2]. It is found that the presence of hydrogen bond will have an important impact on the properties of compounds (boiling point, melting point, surface tension) [3, 4]. Hydrogen bond interaction exists and is often used to explore the mechanism of the ESPT process [5, 6]. However, the dynamic characteristics of the hydrogen bond system in the $S_{1}$ state are more complicated than that of $S_{0}$ state [7]. In general, hydrogen bonds are also important in many biochemical reactions [8]. Recently, the hydrogen bond enhancement theory in the excited sate was proposed by Zhao and Han et al. [9-11]. In particular, when the system has multiple hydrogen bonds, the excited state multidimensional proton transfer is more complicated. Therefore, it is important to study the different mechanisms of hydrogen bond interaction in the $S_{1}$ state.

An important photochemical process, the ESIPT, exists in a four-level photocycle $[12,13]$. In general, the strengthening of hydrogen bond is caused by the change of the acid-base properties of the group under the action of electron density during the photoexcitation process [14]. The premier ESIPT species was first reported by Weller et al. [15]. Since then, ESIPT has shown a variety of potential applications in many biological, chemical, physical and other fields, such as laser dyes [16], white light emitting materials [17], molecular switches [18, 19], fluorescence sensors [20-25] and so on [26, 27]. Moreover, the ESIPT fluorophore is characterized by its ultra-fast time scale [28, 29] and large Stokes displacement [30]. In addition, ESIPT is sensitive to the polarity of solvent and types of solvent [31]. According to this conclusion, the ESIPT and fluorescent mechanisms have been studied by many groups $[11,32,33]$.

In recent years, some derivatives of BPI have been found to have potential applications in laser dyes, highenergy radiation detectors, light stabilizers and so on. Based on 1,3-bis(imino)isoindole diol motif, a new class of ESIPT dyes have been synthesized [34]. The BPI-OH molecule, which contains two intramolecular hydrogen bonds, can occur large Stokes displacement by ESIPT reaction. In the experiment, the electronic spectra of BPI-OH molecules were measured and were compared with the 
Fig. 1 Views of BPI-OH (normal BPI-OH), BPI-OH $\left(\mathrm{T}_{1}\right)$ (single-proton transfer of BPI-OH) and BPI-OH $\left(\mathrm{T}_{2}\right)$ (double-proton transfer of BPI$\mathrm{OH})$. Atom labels involved in two intramolecular hydrogen bonds are marked on BPI-OH structure. Red: $\mathrm{O}$ atom; Blue: $\mathrm{C}$ atom; Gray: $\mathrm{H}$ atom; Orange: $\mathrm{N}$ atom

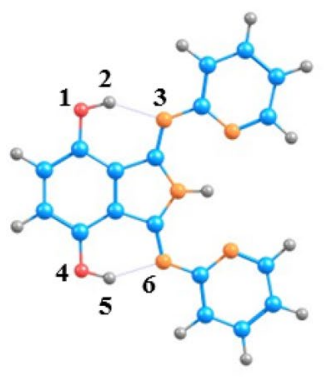

BPI-OH

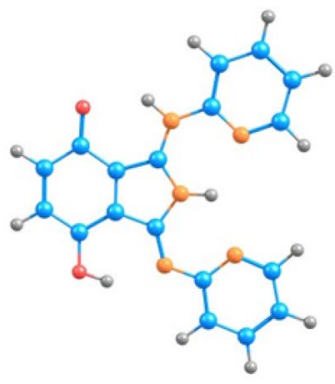

BPI-OH ( $\left.\mathbf{T}_{1}\right)$

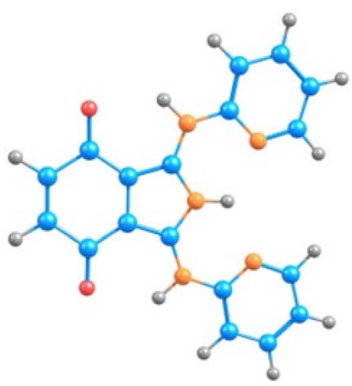

BPI-OH ( $\left.\mathbf{T}_{2}\right)$ derivatives [34]. In the previous study, the reaction mechanism is the step-by-step proton transfer BPI-OH(N) $\rightarrow$ BPI$\mathrm{OH}\left(\mathrm{T}_{1}\right) \rightarrow \mathrm{BPI}-\mathrm{OH}\left(\mathrm{T}_{2}\right)$ [35]. It is further proved that BPI$\mathrm{OH}(\mathrm{N}) \rightarrow \mathrm{BPI}-\mathrm{OH}\left(\mathrm{T}_{1}\right)$ is more prone to proton transfer than $\mathrm{BPI}-\mathrm{OH}\left(\mathrm{T}_{1}\right) \rightarrow \mathrm{BPI}-\mathrm{OH}\left(\mathrm{T}_{2}\right)$. It is worth noting that such structures are sensitive to the surrounding environment. In this paper, the ESIPT mechanism of BPI-OH molecule in dimethyl sulfoxide (DMSO), methanol $(\mathrm{MeOH})$, dichloromethane (DCM) and toluene (TOL) will be studied using DFT and TDDFT. To explore the effect of the different kinds of solvents, the geometric parameters, RDG function have been applied. In addition, the FMOs [36], electro-static potentials and the charge distribution are determined by the Mulliken's charge. The potential energy curves (PECs) is constructed to describe the proton transfer processes. Moreover, to further explore the competition of intramolecular and intermolecular $\mathrm{H}$-bonding, $\mathrm{MeOH}$ as an explicit solvent to study the influence of solvent types on ESIPT process.

\section{Computational details}

All the calculations were used Gaussian 16 program suite [37]. All the computational studies were based on the PCM and the solvation model with integral equation form variables (IEF) [38, 39]. Four kinds of solvents were selected and solvent dielectric constants $(\varepsilon)$ of dimethyl sulfoxide (DMSO), dichloromethane (DCM), methanol (MeOH), and toluene (TOL) is $46.8,32.7,8.9$ and 2.4 , respectively. The geometries of BPI-OH $(\mathrm{N})$, BPI-OH $\left(\mathrm{T}_{1}\right)$ and BPI-OH $\left(\mathrm{T}_{2}\right)$ are optimized using B3LYP $[40,41]$ and TZVP basis set $[42,43]$. There was no virtual frequency. The PECs in the $\mathrm{S}_{0}$ and $\mathrm{S}_{1}$ states were constructed by fixing the $\mathrm{O}_{1}-\mathrm{H}_{2}$ and $\mathrm{O}_{4}-\mathrm{H}_{5}$ distance to further explore the ESIDPT process in four kinds of solvents. We also used Multiwfn software to analyze Mulliken's charge distribution [44, 45].

\section{Results and discussion}

\subsection{Optimized geometric structures, IR vibrational spectra and RDG isosurfaces}

The configurations of BPI-OH, BPI-OH $\left(\mathrm{T}_{1}\right)$ and BPI$\mathrm{OH}\left(\mathrm{T}_{2}\right)$ (shown in Fig. 1) are obtained. The significant parameters involved $\mathrm{O}_{1}-\mathrm{H}_{2} \cdots \mathrm{N}_{3}$ and $\mathrm{O}_{4}-\mathrm{H}_{5} \cdots \mathrm{N}_{6}$ are listed in Table 1. The geometric structure of BPI-OH is symmetrical, the bond length and angle of $\mathrm{O}_{1}-\mathrm{H}_{2} \cdots \mathrm{N}_{3}$ is the same as the corresponding parameters of $\mathrm{O}_{4}-\mathrm{H}_{5} \cdots \mathrm{N}_{6}$. In the $\mathrm{S}_{0}$ state, the bond length of $\mathrm{O}_{1}-\mathrm{H}_{2}$ in four kinds of solvent (DMSO, MeOH, DCM and TOL) is 0.9814, 0.9814, 0.9813 and $0.9808 \AA$, respectively. In the $\mathrm{S}_{1}$ state, the bond length of $\mathrm{O}_{1}-\mathrm{H}_{2}$ is $0.9972,0.9972,0.9975$ and $0.9977 \AA$, respectively. Thus, from $\mathrm{S}_{0}$ to $\mathrm{S}_{1}$ state, the bond of $\mathrm{O}_{1}-\mathrm{H}_{2}$ is weakened, and the hydrogen bond lengths of $\mathrm{H}_{2}-\mathrm{N}_{3}$ in DMSO, MeOH, DCM and TOL solvents are shortened from 2.0592, 2.0592, 2.0590 and $2.0598 \AA$, to 1.9529 , $1.9524,1.9486$ and $1.9425 \AA$, respectively. After photoexcitation, the bond angle of $\mathrm{O}_{1}-\mathrm{H}_{2} \cdots \mathrm{N}_{3}$ are increased from $143.7^{\circ}, 143.7^{\circ}, 143.8^{\circ}$ and $143.8^{\circ}$ in the $S_{0}$ state to
Table 1 Calculated primary bond lengths $(\AA)$ and angles $\left({ }^{\circ}\right)$ of BPI-OH normal structures in the DMSO, MeOH, DCM, TOL solvents

\begin{tabular}{|c|c|c|c|c|c|c|c|c|}
\hline & \multicolumn{2}{|l|}{ DMSO } & \multicolumn{2}{|l|}{$\mathrm{MeOH}$} & \multicolumn{2}{|l|}{ DCM } & \multicolumn{2}{|l|}{ TOL } \\
\hline & $\mathrm{S}_{0}$ & $\mathrm{~S}_{1}$ & $\mathrm{~S}_{0}$ & $\mathrm{~S}_{1}$ & $\mathrm{~S}_{0}$ & $\mathrm{~S}_{1}$ & $\mathrm{~S}_{0}$ & $\mathrm{~S}_{1}$ \\
\hline $\mathrm{O}_{1}-\mathrm{H}_{2}$ & 0.9814 & 0.9972 & 0.9814 & 0.9972 & 0.9813 & 0.9975 & 0.9808 & 0.9977 \\
\hline $\mathrm{H}_{2}-\mathrm{N}_{3}$ & 2.0592 & 1.9529 & 2.0592 & 1.9524 & 2.0590 & 1.9486 & 2.0598 & 1.9425 \\
\hline $\boldsymbol{\delta}\left(\mathrm{O}_{1}-\mathrm{H}_{2}-\mathrm{N}_{3}\right)$ & 143.7703 & 147.2060 & 143.7748 & 147.2255 & 143.7995 & 147.3705 & 143.8052 & 147.6378 \\
\hline $\mathrm{O}_{4}-\mathrm{H}_{5}$ & 0.9814 & 0.9972 & 0.9814 & 0.9972 & 0.9813 & 0.9975 & 0.9808 & 0.9977 \\
\hline $\mathrm{H}_{5}-\mathrm{N}_{6}$ & 2.0592 & 1.9529 & 2.0592 & 1.9524 & 2.0590 & 1.9486 & 2.0598 & 1.9425 \\
\hline $\boldsymbol{\delta}\left(\mathrm{O}_{4}-\mathrm{H}_{5}-\mathrm{N}_{6}\right)$ & 143.7859 & 147.2059 & 143.7912 & 147.2254 & 143.8248 & 147.3705 & 143.8074 & 147.6363 \\
\hline
\end{tabular}




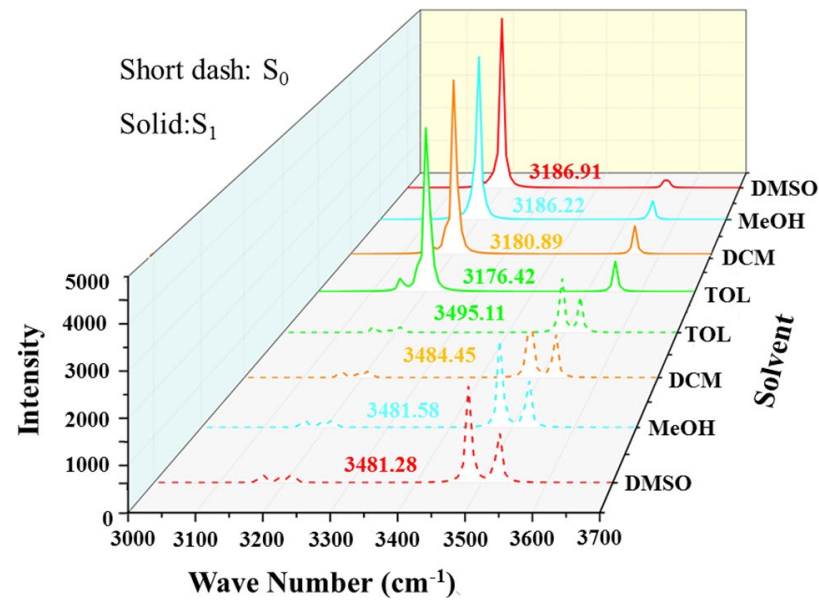

Fig. 2 Calculated stretching vibrational frequencies of the $\mathrm{O}_{1}-\mathrm{H}_{2}$ bond on the $S_{0}$ and $S_{1}$ states in four kinds of solvents (Short dash: $S_{0}$; Solid: $\mathrm{S}_{1}$ )

$147.2^{\circ}, 147.2^{\circ}, 147.4^{\circ}$ and $147.6^{\circ}$ in the $S_{1}$ state in four kinds of solvents. The changes of the geometric structure parameters instruct that the excited-state hydrogen bonding is enhanced, which provides the driving force for the ESIPT reaction. Moreover, with the increase of solvent polarity (from TOL to DMSO), the bond length of $\mathrm{O}_{1}-\mathrm{H}_{2}$ is decreased and the $\mathrm{H}_{2} \cdots \mathrm{N}_{3}$ is increased, which illustrate that the excited-state hydrogen bonding enhancing mechanism with the decrease of solvent dielectric constant.

Infrared vibration frequency is an important index for analyzing the strength of hydrogen bond [46]. Figure 2 shows the infrared vibration frequency of $\mathrm{O}_{1}-\mathrm{H}_{2}$ of BPI$\mathrm{OH}$ molecule in the four kinds of solvents. In DMSO, $\mathrm{MeOH}, \mathrm{DCM}$, TOL, the frequency of $\mathrm{O}_{1}-\mathrm{H}_{2}$ is 3481.28 , $3481.58,3484.45,3495.11 \mathrm{~cm}^{-1}$ in the $\mathrm{S}_{0}$ state and is $3186.91,3186.22,3180.89,3176.42 \mathrm{~cm}^{-1}$ in the $\mathrm{S}_{1}$ state, respectively. The red shift of $294.37,295.36,303.56$ and $318.69 \mathrm{~cm}^{-1}$ is exhibited in the $S_{1}$ state, illustrating the strengthened of hydrogen bond in $S_{1}$ state. Therefore, when the red shift is increased and the excited-state hydrogen bonding is enhanced, the ESIPT is favored with the decrease of solvent dielectric constant.

RDG analysis is a visualized method of weak interaction. Herein, the hydrogen bonds are further analyzed through RDG scatter plots and isosurfaces. As shown in Fig. 3, the hydrogen bond strengthened in TOL $(-0.0312)$ is more obvious than that in DMSO $(-0.0305)$. Thus, as the decrease of dielectric constant, the excited-state hydrogen bonding is strengthened.

\subsection{Electronic spectra, frontier molecular orbitals (FMOs) analysis and Mulliken's charge distribution}

The electronic spectra of BPI-OH are computed in four kinds of solvents. As shown in Fig. 4, the obtained absorption data in DMSO, MeOH, DCM and TOL are 433, 429, 430 and $441 \mathrm{~nm}$, which are agreement with the experimental data $(400-430 \mathrm{~nm})$. Theoretical fluorescence data of the BPI-OH $(\mathrm{N})$ is $511,515,515$ and $500 \mathrm{~nm}$ from DMSO to TOL, respectively, which is close to the emission wavelength of the experiment $(540-575 \mathrm{~nm})$. In the $\mathrm{T}_{1}$ form, the emissions results are 636, 645, 646 and $636 \mathrm{~nm}$ in DMSO, $\mathrm{MeOH}, \mathrm{DCM}$ and TOL. In the $\mathrm{T}_{2}$ form, the corresponding results are 658, 670, 672 and $627 \mathrm{~nm}$. To explore the configuration of double proton transfer, the fluorescence peaks of $\mathrm{T}_{1}$ and $\mathrm{T}_{2}$ are calculated. During ESIPT process, there are double emission fluorescence, accompanied by a large Stokes shift value in DMSO (125 nm), MeOH (130 nm), DCM $(131 \mathrm{~nm})$ and TOL $(136 \mathrm{~nm})$, respectively. As the dielectric constant decreases, the Stokes shift increases. After photoexcitation, the transition and redistribution of electrons could occur [47]. The MOs of BPI-OH molecules in DMSO, MeOH, DCM and TOL solvents are shown in Fig. 5. The calculated wavelengths, corresponding oscillator strength (f) are listed in Table S1. The first comprehensive TDDFT study (in DCM) on BPI-OH was reported by Chai et al. [48]. However, the vertical excitation energy calculated by us in DCM solution $(2.87 \mathrm{eV})$ is closer to the experimental value $(2.88 \mathrm{eV})$ than that calculated by Chai et al. $(2.96 \mathrm{eV})$. Herein, the HOMO and the LUMO, lead to the distinct $\pi \rightarrow \pi^{*}$ feature of $S_{0} \rightarrow S_{1}$ transition. The chemical activity can be expressed by the energy gap between HOMO and LUMO. The low kinetic stability and high chemical activity are indicated by small energy gaps $[49,50]$. The energy gap is $2.888,2.885,2.882$ and $2.858 \mathrm{eV}$, respectively, in DMSO, MeOH, DCM and TOL. Thus, the solvent polarity has effect on the electron transition and energy gap. In addition, the electron density of the BPI-OH molecules in four kinds of solvents are also changed, and the electron density on $\mathrm{O}_{1}$ decreases, while that on $\mathrm{N}_{3}$ increases, which facilitates the transfer of proton $\mathrm{H}_{2}$ from $\mathrm{O}_{1}$ to $\mathrm{N}_{3}$. In fact, the trend and process of ESDPT can be explained by subtle changes in electron density.

Meanwhile, $\mathrm{S}$ represents the space separation of holes and electrons, and D represents the length of charge transfer, and these values were listed in Table $\mathrm{S} 2$. The $\Delta r$ indexes are $1.969,1.977,1.989$, and $2.037 \AA$ in $\mathrm{DMSO}, \mathrm{MeOH}$, DCM and TOL solvents, respectively. The $S$ values are $0.672,0.672,0.671$ and 0.669 from DMSO to TOL. The $D$ values are $1.970,1.976,1.989$ and $2.037 \AA$ from DMSO to TOL (as shown in Fig. S1). It is obvious that the charge transfer length increases with the decrease of solvent 
Fig. 3 RDG scatter plot of the $\mathrm{S}_{1}$ state and isosurface for BPI$\mathrm{OH}$ in four kinds of solvents; a DMSO; b MeOH; c DCM; $d$ TOL. The color gradient corresponding to the diverse types of the interaction have been shown in the figure legend
H-bond Van der Waals Repulsion

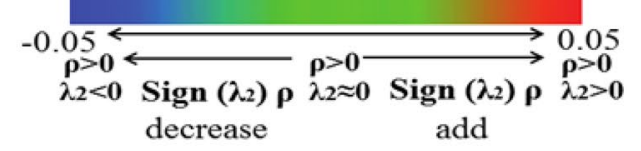

(a) DMSO

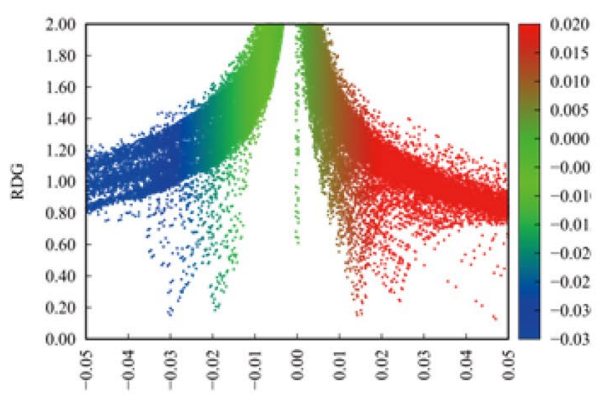

$\operatorname{sign}\left(l_{2}\right) r($ a.u. $)$

(b) $\mathrm{MeOH}$
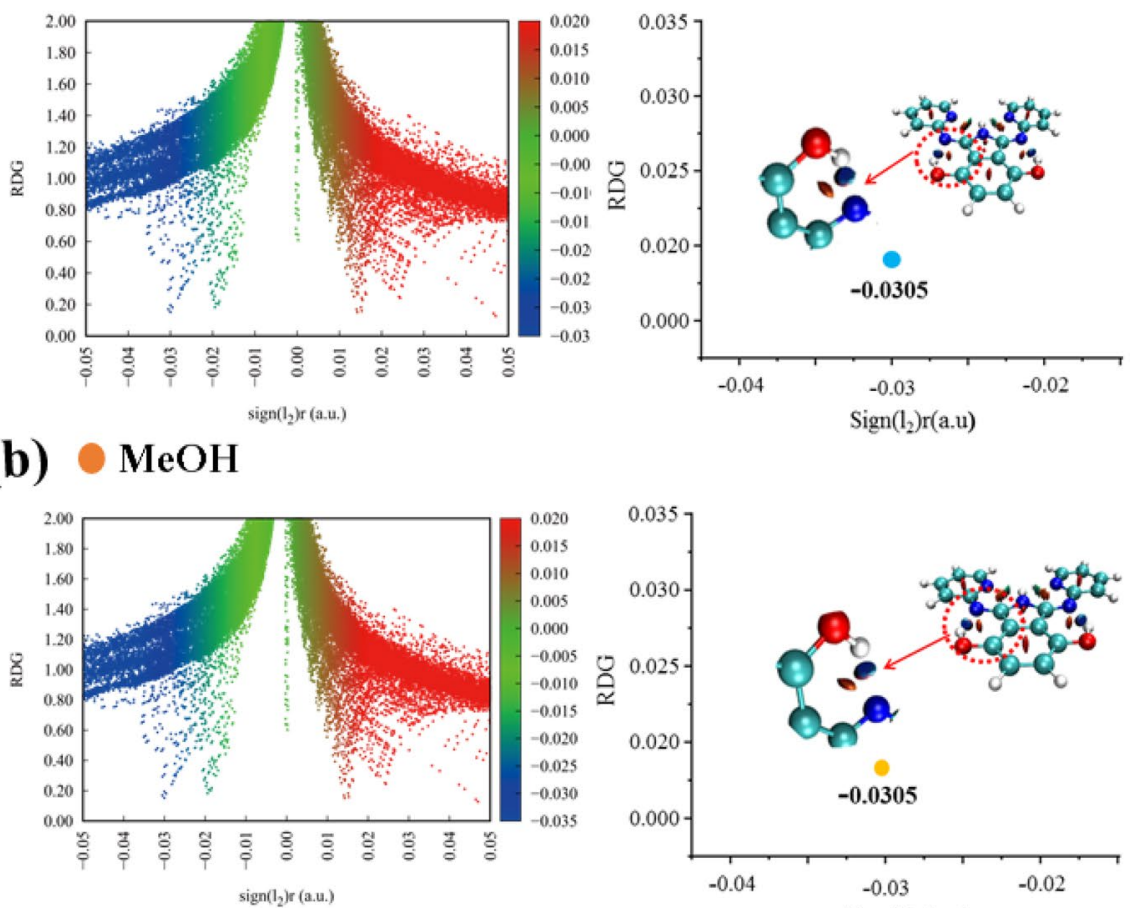

(c) $\bigcirc \mathrm{DCM}$

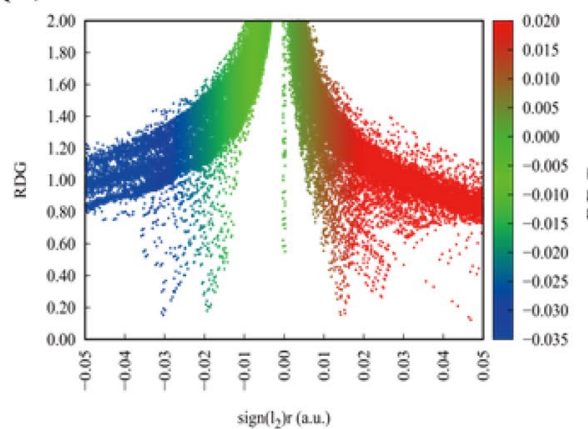

(d) $\bigcirc \mathrm{TOL}$

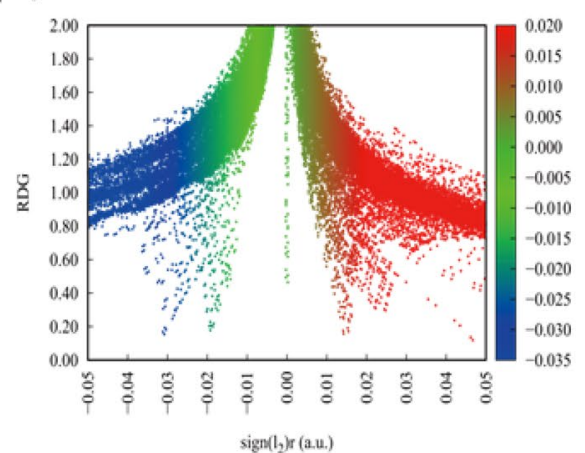

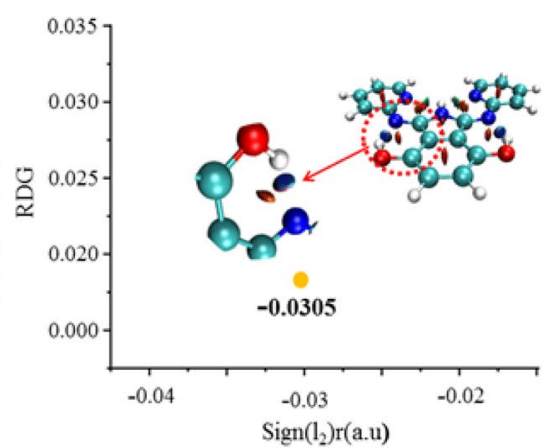
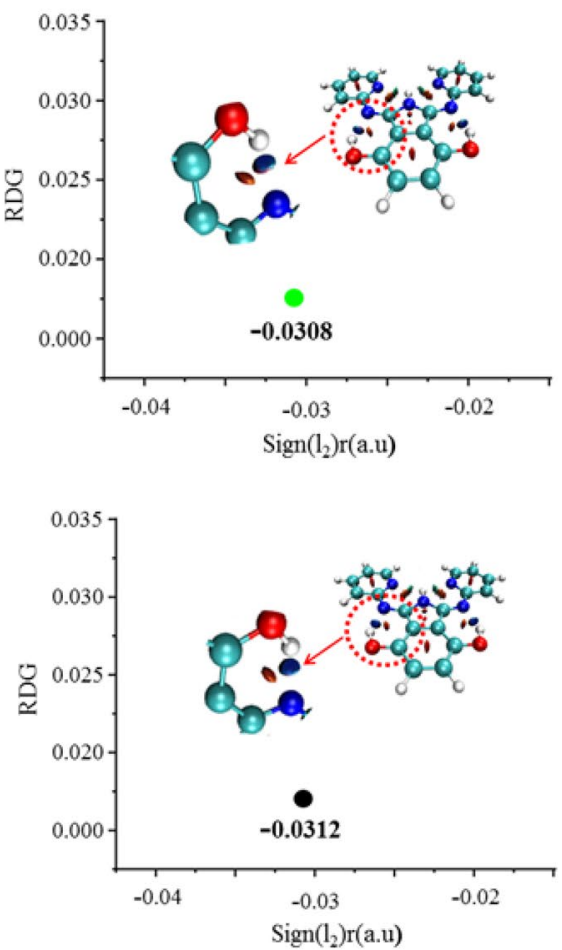
Fig. 4 Calculated absorption (abs) and fluorescence (flu) wavelength of BPI-OH in different kinds of solvents; a DMSO; b $\mathrm{MeOH}$; $\mathbf{~ D C M}$; d TOL; $\mathrm{N}$ : normal form; $\mathrm{T}_{1}$ and $\mathrm{T}_{2}$ : tautomer form

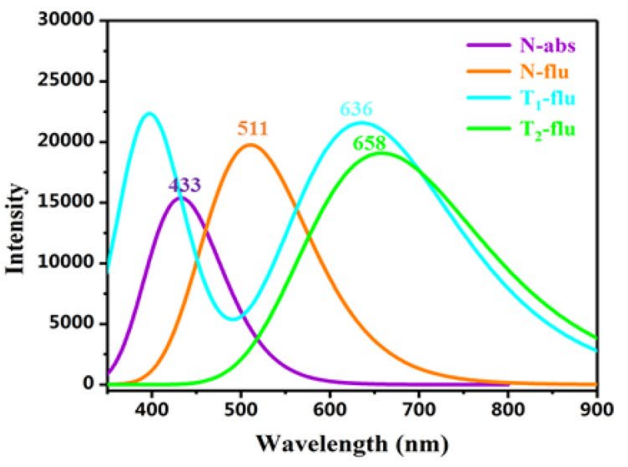

(a)

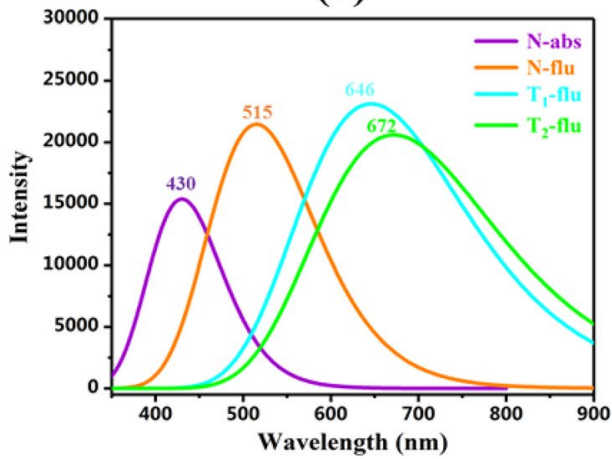

(c)

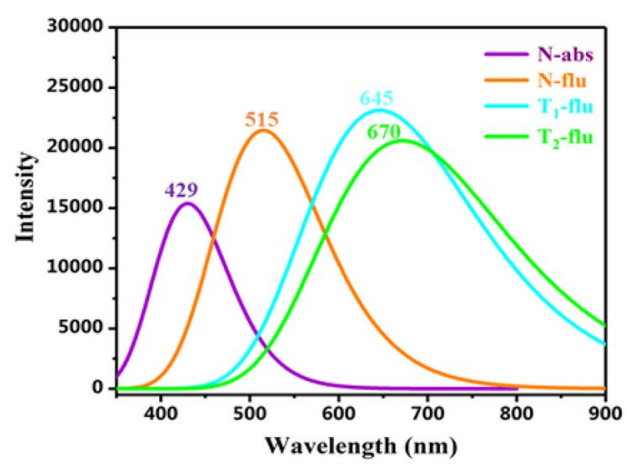

(b)

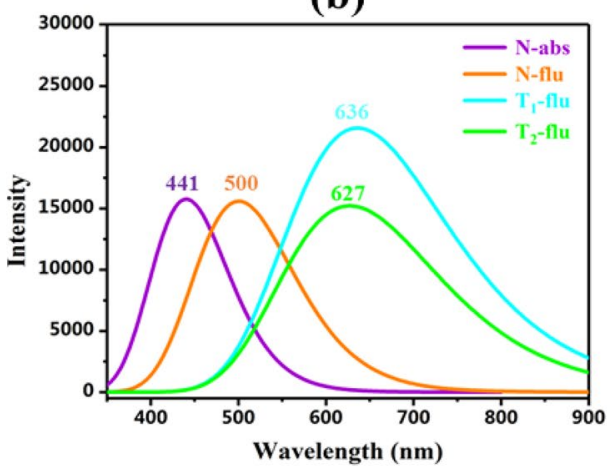

(d)

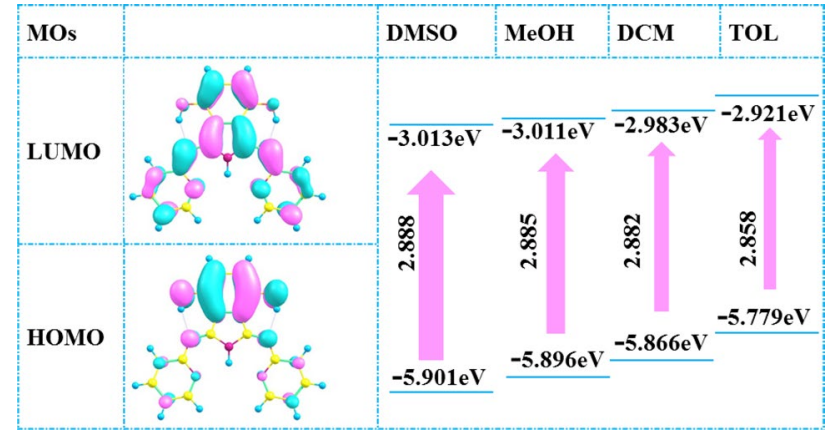

Fig. 5 Calculated frontier molecular orbitals (HOMO and LUMO) of BPI-OH on the $\mathrm{S}_{1}$ state and its transition energy

polarity. As listed in Table 2, in DMSO, the Mulliken's charge of $\mathrm{O}_{1}$ is decreased from -0.298 to -0.288 and $\mathrm{N}_{3}$ is increased from -0.221 to -0.230 , which indicates the electronegativity of $\mathrm{N}_{3}$ increased and that of $\mathrm{O}_{1}$ decreased. Thus, the ESIPT reaction is affected by charge density. Since Mulliken's charges are very sensitive to the choice of basis set, to eliminate this effect, Aug-cc-pVTZ basis set is used. The charge of $\mathrm{O}_{1}$ atom changes from -0.097 to -0.830 during the $S_{0}$ to $S_{1}$ states in DMSO solvent. The reduced electronegativity of $\mathrm{O}$ atom indicates that the attraction of the donor to $\mathrm{H}$ atom is reduced during photoexcitation process, which promotes the occurrence of $\mathrm{H}$ proton transfer. Therefore, the same conclusions can be obtained.

\subsection{Potential energy curves of the proton transfer reactions}

In previous reports, it was found that the double protons in BPI-OH molecules follow a step-by-step transfer mechanism. Potential energy curves are constructed in four kinds of solvents with a function of $\mathrm{O}_{1}-\mathrm{H}_{2}$ bond length
Table 2 Calculated Mulliken's charge distribution of molecule BPI-OH in $\mathrm{S}_{0}$ and $\mathrm{S}_{1}$ states

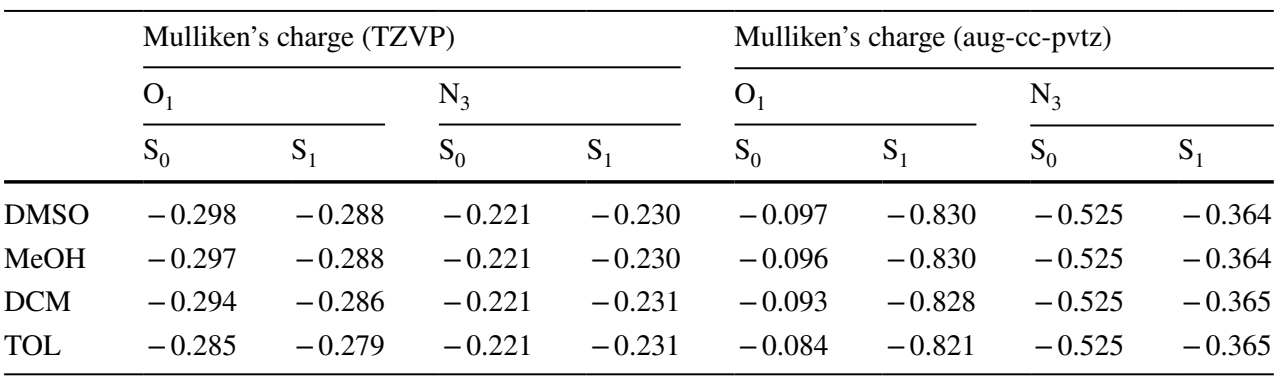


Fig. 6 Potential energy curves of $\mathrm{S}_{0}$ and $\mathrm{S}_{1}$ states of BPI-OH as a function $\mathrm{O}_{1}-\mathrm{H}_{2}$ bond length in different kinds of solvents; a DMSO; b $\mathrm{MeOH}$; c DCM; d TOL
Fig. 7 Potential energy curves of $\mathrm{S}_{0}$ and $\mathrm{S}_{1}$ states of BPI-OH $\left(\mathrm{T}_{1}\right)$ as a function $\mathrm{O}_{4}-\mathrm{H}_{5}$ bond length in different kinds of solvents; a DMSO; b MeOH; c DCM; d TOL
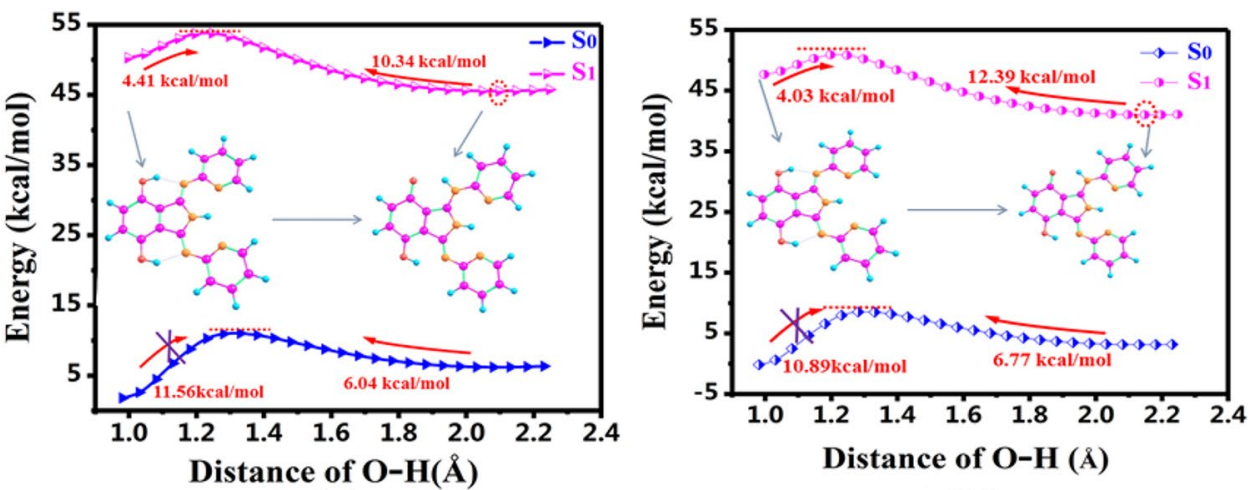

(a)

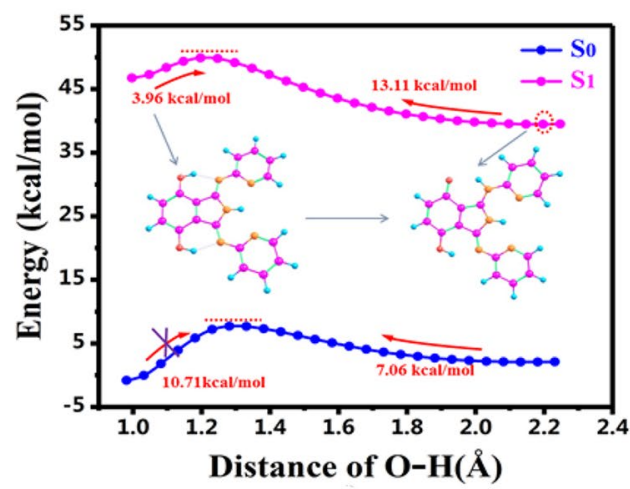

(c)

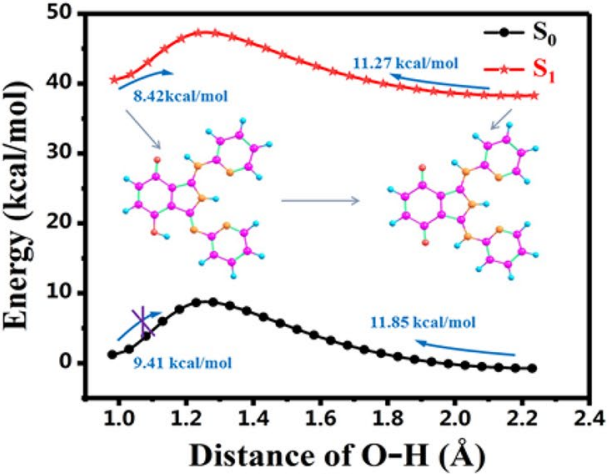

(a)

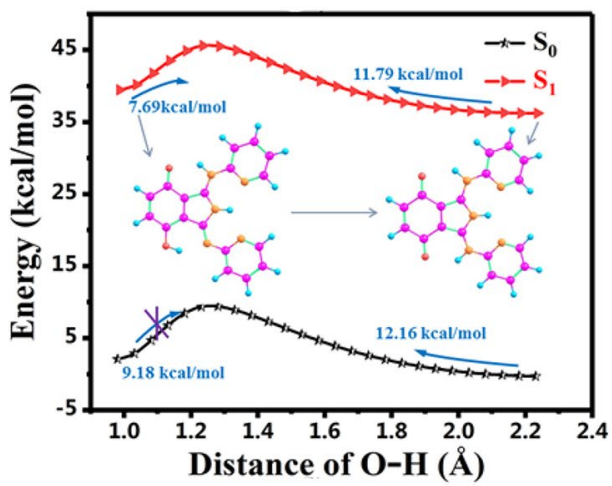

(c)

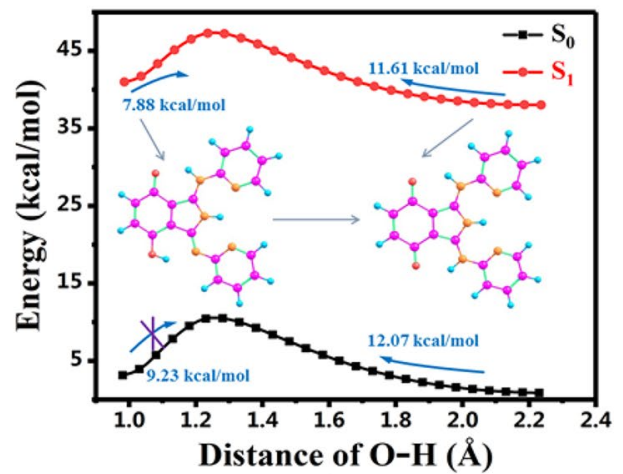

(b)

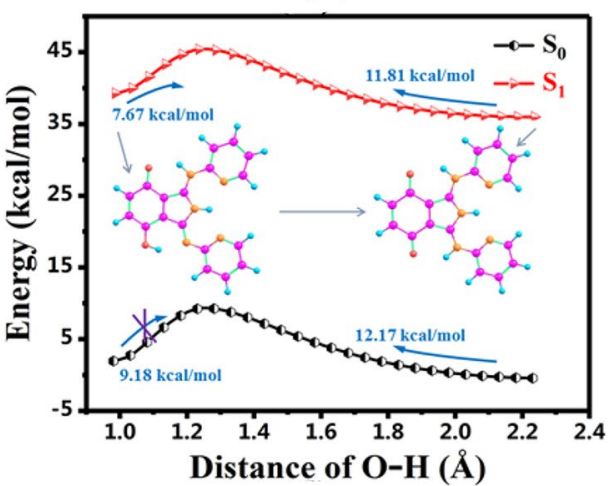

(d) 


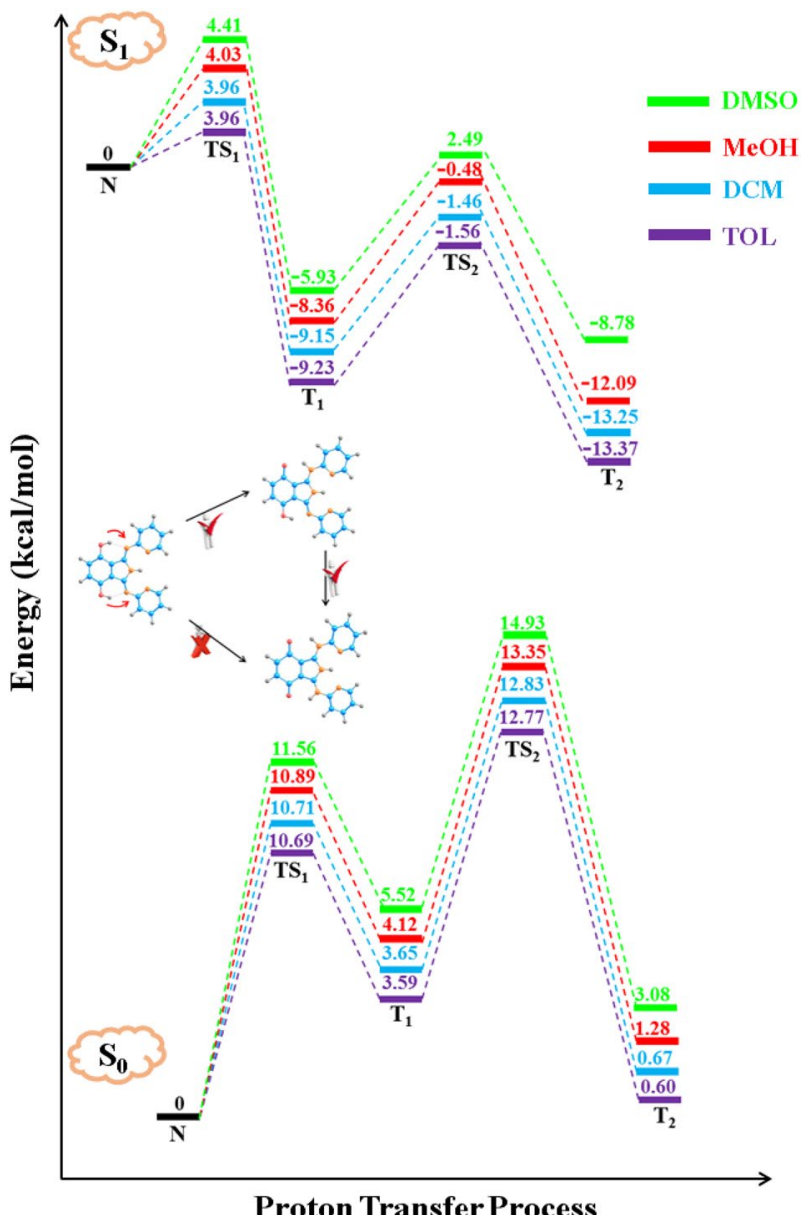

Fig. 8 Proton transfer processes of the BPI-OH molecule in four kinds of solvents in $S_{0}$ and $S_{1}$ states and $\mathrm{O}_{4}-\mathrm{H}_{5}$ bond length at B3LYP/TZVP level, as depicted in Figs. 6 and 7. As shown in Fig. 6, potential reaction energy $\left(\mathrm{BPI}-\mathrm{OH}(\mathrm{N}) \rightarrow \mathrm{BPI}-\mathrm{OH}\left(\mathrm{T}_{1}\right)\right)$ in the $\mathrm{S}_{0}$ state in DMSO, MeOH, DCM and TOL is $11.56,10.89,10.71$ and $10.69 \mathrm{kcal} \mathrm{mol}^{-1}$, respectively. It can be seen that the potential barrier for proton transfer in $S_{0}$ state is high, which is not conducive to proton transfer reaction. In the $\mathrm{S}_{1}$ state, the energies of $\mathrm{T}_{1}$ structure are lower than that of $\mathrm{N}$ structures in four kinds of solvents, which suggests that the thermodynamic feasibility of ESIPT process. In the $S_{1}$ state, the ESIPT energy barriers in DMSO, MeOH, DCM and TOL are 4.41, 4.03, 3.96, $3.96 \mathrm{kcal} \mathrm{mol}^{-1}$, respectively. The potential barriers of reverse ESIPT reactions in DMSO, MeOH, DCM and TOL is 10.34, 12.39, 13.11 and $13.19 \mathrm{kcal} \mathrm{mol}^{-1}$, respectively. Thus, it is difficult to occur the reverse proton transfer. The increase of the dielectric constant of the solvent will lead to the weakening of hydrogen bond strength and ESIPT reaction is difficult to proceed. Thus, among the four solvents, TOL is more suitable for proton transfer reaction.

As shown in Fig. 7, for BPI-OH $\left(\mathrm{T}_{1}\right) \rightarrow \mathrm{BPI}-\mathrm{OH}\left(\mathrm{T}_{2}\right)$, the energies $T_{2}$ structure are lower than that enol structure $\left(T_{1}\right)$ in four kinds of solvents in the $\mathrm{S}_{1}$ state. The ESIPT energy barriers in DMSO, MeOH, DCM and TOL are 8.42, 7.88, $7.69,7.67 \mathrm{kcal} \mathrm{mol}^{-1}$, respectively. It is not difficult to see that the proton transfer process of the second step is inhibited to some extent with the increase of solvent polarity. The results are similar to those reported by Chai et al. [48] using DCM as a solvent. This further confirms the accuracy of our other studies. For the second step, the solvent TOL is more favorable for the reaction. In addition, in the two-step proton transfer reactions, the relative energy barrier of the influence
Table 3 Calculated bond lengths $(\AA)$ and angles $\left(^{\circ}\right)$ of BPI-OH-MeOH (N), BPI-OH$\mathrm{MeOH}\left(\mathrm{T}_{1}\right)$, and BPI-OH$\mathrm{MeOH}\left(\mathrm{T}_{2}\right)$ in the $\mathrm{S}_{0}$ state and the $S_{1}$ state, respectively

\begin{tabular}{|c|c|c|c|c|c|c|}
\hline & \multicolumn{2}{|c|}{ BPI-OH-MeOH (N) } & \multicolumn{2}{|c|}{$\mathrm{BPI}-\mathrm{OH}-\mathrm{MeOH}\left(\mathrm{T}_{1}\right)$} & \multicolumn{2}{|c|}{$\mathrm{BPI}-\mathrm{OH}-\mathrm{MeOH}\left(\mathrm{T}_{2}\right)$} \\
\hline & $\mathrm{S}_{0}$ & $\mathrm{~S}_{1}$ & $\mathrm{~S}_{0}$ & $\mathrm{~S}_{1}$ & $\mathrm{~S}_{0}$ & $\mathrm{~S}_{1}$ \\
\hline $\mathrm{O}_{1}-\mathrm{H}_{2}$ & 0.9848 & 1.0033 & 2.1285 & 2.6798 & 2.2581 & 2.5283 \\
\hline $\mathrm{H}_{2}-\mathrm{N}_{3}$ & 2.0255 & 1.9073 & 1.0217 & 1.0325 & 1.0158 & 1.0266 \\
\hline $\mathrm{O}_{5}-\mathrm{H}_{4}$ & 0.9688 & 0.9661 & 0.9792 & 0.9861 & 0.9759 & 0.9820 \\
\hline $\mathrm{H}_{4}-\mathrm{O}_{1}$ & 1.9888 & 2.1007 & 1.7817 & 1.6720 & 1.8048 & 1.7047 \\
\hline $\boldsymbol{\delta}\left(\mathrm{O}_{1}-\mathrm{H}_{2}-\mathrm{N}_{3}\right)$ & 144.1 & 147.9 & 133.3 & 118.5 & 129.1 & 119.6 \\
\hline $\boldsymbol{\delta}\left(\mathrm{O}_{5}-\mathrm{H}_{4}-\mathrm{O}_{1}\right)$ & 159.7 & 152.7 & 169.1 & 164.7 & 169.1 & 161.1 \\
\hline $\mathrm{O}_{6}-\mathrm{H}_{7}$ & 0.9847 & 1.0030 & 0.9827 & 0.9986 & 2.2523 & 2.5250 \\
\hline $\mathrm{H}_{7}-\mathrm{N}_{8}$ & 2.0278 & 1.9105 & 2.0706 & 1.8643 & 1.0159 & 1.0266 \\
\hline $\mathrm{O}_{10}-\mathrm{H}_{9}$ & 0.9689 & 0.9662 & 0.9684 & 0.9682 & 0.9760 & 0.9821 \\
\hline $\mathrm{H}_{9}-\mathrm{O}_{6}$ & 1.9827 & 2.1039 & 2.0045 & 2.0065 & 1.8012 & 1.7052 \\
\hline $\boldsymbol{\delta}\left(\mathrm{O}_{6}-\mathrm{H}_{7}-\mathrm{N}_{8}\right)$ & 144.1 & 147.9 & 142.9 & 148.1 & 129.3 & 119.5 \\
\hline $\boldsymbol{\delta}\left(\mathrm{O}_{10}-\mathrm{H}_{9}-\mathrm{O}_{6}\right)$ & 160.3 & 152.6 & 161.7 & 156.7 & 168.3 & 160.9 \\
\hline
\end{tabular}




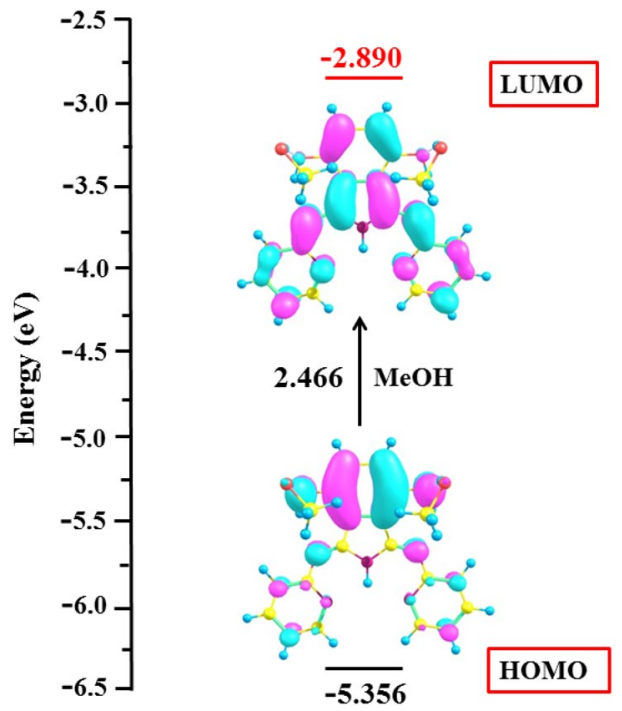

Fig. 9 Frontier molecular orbitals (HOMO and LUMO) of BPI-OH$\mathrm{MeOH}(\mathrm{N})$

of the solvent is 0.45 and $0.75 \mathrm{kcal} / \mathrm{mol}$, respectively, which indicates that the solvent TOL has a greater influence on the second step proton transfer. In the $\mathrm{S}_{1}$ state, for the two-step proton transfer reaction, the reaction barrier of the second proton transfer is higher than that of the first proton transfer. In the BPI-OH system, the ESIPT can be happened to form BPI-OH $\left(\mathrm{T}_{1}\right)$ or BPI-OH $\left(\mathrm{T}_{2}\right)$ in $\mathrm{S}_{1}$ state through proton transfer path (BPI-OH $(\mathrm{N}) \rightarrow$ BPI-OH $\left(\mathrm{T}_{1}\right) \rightarrow$ BPI-OH $\left(\mathrm{T}_{2}\right)$ ). In addition, BPI-OH $\left(\mathrm{T}_{1}\right)$ and BPI-OH $\left(\mathrm{T}_{2}\right)$ return to the $\mathrm{S}_{0}$ state by a radiative transition. The relative high energy barrier prevents BPI-OH $\left(\mathrm{T}_{1}\right)$ and BPI-OH $\left(\mathrm{T}_{2}\right)$ molecules from undergoing a reverse proton transfer. Meanwhile, we also show the intramolecular proton processes of the whole molecule in the $S_{0}$ and $S_{1}$ states (Fig. 8).

\subsection{BPI-OH-MeOH complex}

Then, the effect of explicit solvent (methanol) on the excited state properties of BPI-OH compound are investigated, and we optimized the $\mathrm{N}, \mathrm{T}_{1}$ and $\mathrm{T}_{2}$ forms of $\mathrm{BPI}-\mathrm{OH}-\mathrm{MeOH}$ (shown in Fig. S2). In view of previous reports, methanol molecules were also considered at the donor site in this study $[51,52]$. The significant parameters of the BPI-OH-MeOH$\mathrm{N}, \mathrm{BPI}-\mathrm{OH}-\mathrm{MeOH}-\mathrm{T}_{1}$ and BPI-OH-MeOH-T are listed in Table 3. For example, the $\mathrm{O}_{1}-\mathrm{H}_{2}$ bond length change from $0.9848 \AA$ in the $\mathrm{S}_{0}$ state to $1.0033 \AA$ in the $\mathrm{S}_{1}$ state (increasing $0.0185 \AA$ ) and the $\mathrm{H}_{2}-\mathrm{N}_{3}$ bond length change from $2.0255 \AA$ in the $\mathrm{S}_{0}$ state to $1.9073 \AA$ in the $\mathrm{S}_{1}$ state (decreasing $0.1182 \AA$ ) for BPI-OH-MeOH $(\mathrm{N})$. Meanwhile, the $\mathrm{O}_{5}-\mathrm{H}_{4}$ bond length change from $0.9688 \AA$ in the $\mathrm{S}_{0}$ state to $0.9611 \AA$ in the $S_{1}$ state (decreasing $0.0077 \AA$ ) and the $\mathrm{H}_{4}-\mathrm{O}_{1}$ bond length change from $1.9888 \AA$ in the $\mathrm{S}_{0}$ state to $2.1007 \AA$ in the $S_{1}$ state (increasing $0.1119 \AA$ ). The changes of the geometric structure parameters instruct that the hydrogen bond is enhanced and the change values of bond length and angle of compound BPI-OH in explicit solvents is more obvious than that in implicit solvents, in the $S_{1}$ state. That is because compound BPI-OH is subjected to more hydrogen bonding forces in explicit solvent (methanol).

The absorption and emission spectra of BPI-OH-MeOH complex are computed (shown in Fig. S3), which are in good agreement with the spectra provided in the experiment [34]. Meanwhile, the FMOs of BPI-OH-MeOH (N) are shown in Fig. 9. The calculated wavelengths, corresponding oscillator strength $(f)$ are listed in Table S3. Herein, the HOMO and LUMO, lead to the distinct $\pi \rightarrow \pi^{*}$ feature of $S_{0} \rightarrow S_{1}$ transition. The energy gap is $2.466 \mathrm{eV}$, which is lower than that of other implicit solvents, indicating higher stability of the $\mathrm{BPI}-\mathrm{OH}-\mathrm{MeOH}$ complex in the explicit solvent.

PECs were constructed to gain the effects of explicit solvent on ESIPT (shown in Fig. 10). The reaction barrier for $\mathrm{BPI}-\mathrm{OH}-\mathrm{MeOH}(\mathrm{N}) \rightarrow \mathrm{BPI}-\mathrm{OH}-\mathrm{MeOH}\left(\mathrm{T}_{1}\right)$ is $0.91 \mathrm{kcal} / \mathrm{mol}$ in the $\mathrm{S}_{1}$ state. Then, the energy barrier of proton transfer reaction from BPI-OH-MeOH $\left(\mathrm{T}_{1}\right)$ to $\mathrm{BPI}-\mathrm{OH}-\mathrm{MeOH}\left(\mathrm{T}_{2}\right)$ in the $\mathrm{S}_{1}$ state is $1.23 \mathrm{kcal} / \mathrm{mol}$. Importantly, the complex is more likely to undergo the ESIPT process in explicit solvents than in implicit solvents, because it is subjected to more intermolecular hydrogen bonding in explicit solvents.
Fig. 10 Potential energy curves of the $\mathrm{S}_{0}$ and $\mathrm{S}_{1}$ states for BPI-OH-MeOH complex along with the $\mathrm{O}_{1}-\mathrm{H}_{2}$ and the $\mathrm{O}_{6}-\mathrm{H}_{7}$ bond lengths. (a) BPI-OH$\mathrm{MeOH}(\mathrm{N}) \rightarrow$ BPI-OH-MeOH $\left(\mathrm{T}_{1}\right)$; (b) BPI-OH-MeOH $\left(\mathrm{T}_{1}\right) \rightarrow$ BPI-OH-MeOH $\left(\mathrm{T}_{2}\right)$

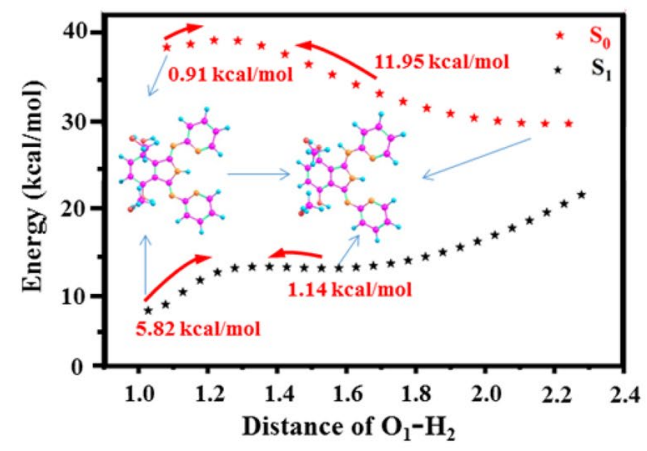

(a)

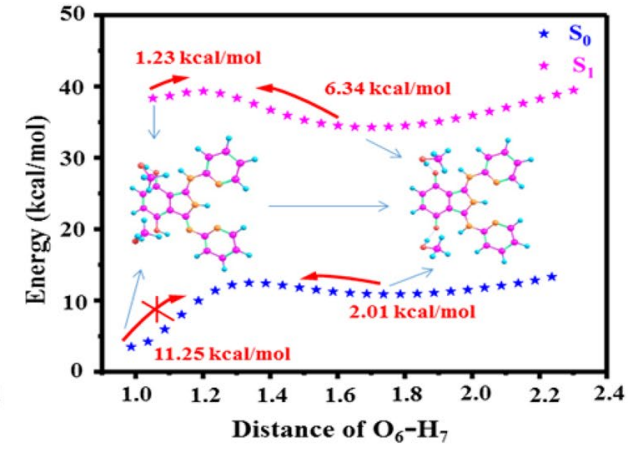

(b) 
Fig. 11 a RDG scatter plot of the $\mathrm{S}_{0}$ state for BPI-OH-MeOH; b RDG partial magnification scatter plot and isosurface in $\mathrm{MeOH}$ solvent; c RDG scatter plot of the $S_{1}$ state for BPI$\mathrm{OH}-\mathrm{MeOH}$; d RDG partial magnification scatter plot and isosurface in $\mathrm{MeOH}$ solvent

H-bond Van der Waals Repulsion

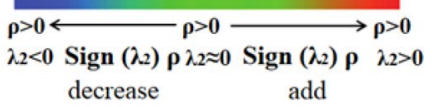

(a)

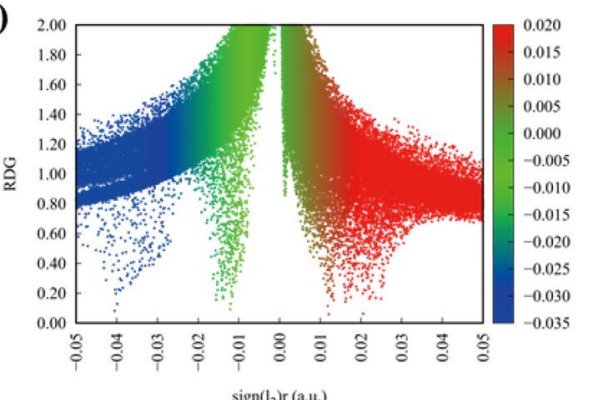

(c)

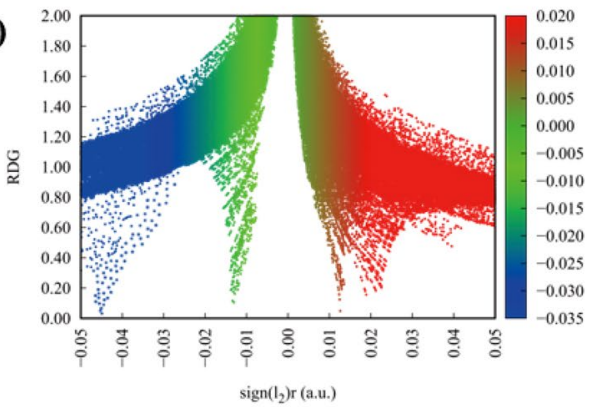

(b)

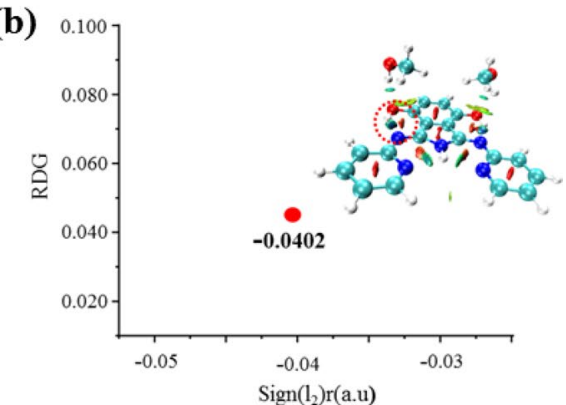

(d)

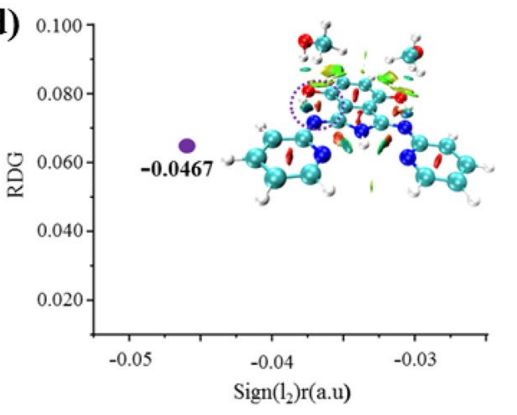

To verify our conjecture, we have performed RDG analysis on the explicit solvent of the BPI-OH-MeOH complex.

The hydrogen bonds of BPI-OH-MeOH forms $(-0.0402)$ in the $\mathrm{S}_{0}$ state are significantly stronger than that in implicit solvents (DMSO: -0.0305 ; $\mathrm{MeOH}:-0.0305$; DCM:-0.0308; TOL: -0.0312 ), especially in the $\mathrm{S}_{1}$ state (BPI-OH-MeOH form is - 0.0467) (shown in Fig. 11b, d). Thus, the type of solvent has a more significant effect on hydrogen bond, which also confirms our above conjecture that $\mathrm{BPI}-\mathrm{OH}-\mathrm{MeOH}$ complex is subjected to intermolecular hydrogen bond interactions in the explicit solvent.

\section{Conclusion}

In conclusion, from the theoretical perspective, we studied the impacts of the solvent polarity and solvent type on the ESIDPT for the BPI-OH molecule. In four kinds of solvents, the hydrogen bonding parameters, RDG analysis and IR spectra of the BPI-OH have been calculated, which illustrate that the strengthening of excited-state $\mathrm{H}$-bonding. The excited-state hydrogen bonding strengthened follows the trend: DMSO $<\mathrm{MeOH}<\mathrm{DCM}<\mathrm{TOL}$. Meanwhile, according to $\mathrm{FMO}_{\mathrm{S}}$ and PECs in the $\mathrm{S}_{1}$ state, as the polarity solvent decrease, ESIPT reaction is favorable to occur. Moreover, in explicit (methanol) solvent, the ESIPT process of BPI-OH-MeOH complex is carried out very little energy potential barrier, which is easier to occur than that in implicit solvent. In addition, isomers BPI-OH $\left(\mathrm{T}_{1}\right)$ and BPI-OH $\left(\mathrm{T}_{2}\right)$ can be got through a step-by-step process BPI$\mathrm{OH}(\mathrm{N}) \rightarrow \mathrm{BPI}-\mathrm{OH}\left(\mathrm{T}_{1}\right) \rightarrow \mathrm{BPI}-\mathrm{OH}\left(\mathrm{T}_{2}\right)$, which reveals a stepwise ESDPT process.

Supplementary Information The online version contains supplementary material available at https://doi.org/10.1007/s43630-021-00091-1.

Funding This work was supported by the Open Project of SKLMRD (the open fund of the state key laboratory of molecular reaction dynamics in DICP, CAS) and National Natural Science Foundation of China (Grant 31771914).

\section{Declarations}

Conflict of interest There is no conflict of interest.

\section{References}

1. Guo, Z., Park, S., Yoon, J., \& Shin, I. (2014). Recent progress in the development of near- infrared fluorescent probes for bioimaging applications. Chemical Society Reviews, 43, 16-29.

2. Sobolewski, A., Domcke, W., Dedonder-Lardeux, C., \& Jouvet, C. (2002). Excited-state hydrogen detachment and hydrogen transfer driven by repulsive $1 \pi \sigma^{*}$ states: A new paradigm for nonradiative decay in aromatic biomolecules. Physical Chemistry Chemical Physics: PCCP, 4, 1093-1100.

3. Zhao, G. J., \& Han, K. L. (2012). Hydrogen bonding in the electronic excited state. Accounts of Chemical Research, 45, 404-413. 
4. Zhao, J. F., \& Jin, B. (2021). Effects of solvent polarity on excited state behaviors for the two intramolecular proton-transfer-site 4,4' -(hydrazine-1,2-diylidene-bis(methanylylidene))-bis(3hydroxybenzoic acid) compound. Journal of Luminescence, 232, 117800 .

5. Chen, Y. P., Yang, Y. F., Zhao, Y., Liu, S. X., \& Li, Y. Q. (2019). Effect of solvent environment on excited state intramolecular proton transfer in 2-(4-(dimethylamino)phenyl)-3-hydroxy-6,7dimethoxy-4h-chromen-4-one. Physical Chemistry Chemical Physics: PCCP, 21, 17711-17719.

6. Zhao, Y., Ding, Y., Yang, Y. F., Shi, W., \& Li, Y. Q. (2019). Fluorescence deactivation mechanism for a new probe detecting phosgene based on ESIPT and TICT. Organic Chemistry Frontiers, 6, 597-602.

7. Tang, Z., \& Zhou, P. (2020). New insights into the excited state dynamics of quinoline-pyrazole isomerism. The Journal of Physical Chemistry B, 124, 3400-3407.

8. Zhang, Y. J., Zhao, J. F., \& Li, Y. Q. (2016). The investigation of excited state proton transfer mechanism in water-bridged 7-azaindole. Spectrochimica Acta, Part A: Molecular and Biomolecular Spectroscopy, 153, 147-151.

9. Qi, Y. T., Tang, Z., Zhan, H. B., Wang, Y., Zhao, Y., Xu, F., Jing, T. N., Ling, Y. D., \& Liu, J. Y. (2020). A new interpretation of the ESIPT mechanism of 2-(benzimidazol-2-yl)-3-hydroxychromone derivatives. Spectrochimica Acta A Molecular and Biomolecular Spectroscopy, 224, 117359.

10. Zhao, G. J., \& Han, K. L. (2010). PH-controlled twisted intramolecular charge transfer (TICT) excited state via changing the charge transfer direction. Physical Chemistry Chemical Physics: PCCP, 12, 8914-8918.

11. Zhou, P. W., \& Han, K. L. (2018). Unraveling the detailed mechanism of excited-state proton transfer. Accounts of Chemical Research, 51, 1681-1690.

12. Chen, Y. P., Yang, Y. F., Zhao, Y., Liu, S. X., \& Li, Y. Q. (2019). YQ, The effect of different environments on excited-state intramolecular proton transfer in 4 '-methoxy-3-hydroxyflavone. Organic Chemistry Frontiers, 6, 18-225.

13. Yang, Y. F., Chen, Y. P., Zhao, Y., Shi, W., Ma, F. C., \& Li, Y. Q. (2019). Under different solvents excited-state intramolecular proton transfer mechanism and solvatochromic effect of 2-(2-hydroxyphenyl) benzothiazole molecule. Journal of Luminescence, 206, 326-334.

14. Stasyuk, A. J., Cyranski, M. K., Gryko, D. T., \& Sola, M. (2015). Imidazo 1,2-a pyridines susceptible to excited state intramolecular proton transfer: One-pot synthesis via an ortoleva-king reaction. Journal of Chemical Theory and Computation, 11, 1046-1054.

15. Weller, A. (1956). Innermolekularer protonenubergang im angeregten zustand. Zeitschrift Fur Elektrochemie, 60, 1144.

16. Chou, P., McMorrow, D., Aartsma, T. J., \& Kasha, M. (1984). The proton-transfer laser - gain spectrum and amplification of spontaneous emission of 3-hydroxyflavone. Journal of Physical Chemistry, 88, 4596.

17. Tseng, H. W., Liu, J. Q., Chen, Y. A., Chao, C. M., Liu, K. M., Chen, C. L., Lin, T. C., Hung, C. H., Chou, Y. L., Wang, T. L., \& Chou, P. T. (2015). Harnessing excited-state intramolecular proton-transfer reaction via a series of amino-type hydrogen-bonding molecules. Journal of Physical Chemistry Letters, 6, 1477.

18. Irie, M. (2000). Diarylethenes for memories and switches. Chemical Reviews, 100, 1685-1716.

19. Irie, M. (2000). Photochromism: memories and switches - introduction. Chemical Reviews, 100, 1683-1684.

20. Zhao, J., Ji, S., Chen, Y., Guo, H., \& Yang, P. (2012). Excited state intramolecular proton transfer (ESIPT): From principal photophysics to the development of new chromophores and applications in fluorescent molecular probes and luminescent materials. Physical Chemistry Chemical Physics: PCCP, 14, 8803-8817.
21. An, B. B., Song, S. Y., Wen, K. K., Wu, W. P., Yuan, H. J., Zhu, Q. L., Guo, X. G., \& Zhang, J. L. (2017). Theoretical insights into the ultrafast excited-state intramolecular proton transfer (ESIPT) mechanism in a series of amide-based $\mathrm{N} \mathrm{H} \bullet \bullet \mathrm{N}$ hydrogen-bonding compounds. Organic Electron, 45, 1-8.

22. Roshal, A. D., Grigorovich, A. V., Doroshenko, A. O., Pivovarenko, V. G., \& Demchenko, A. P. (1998). Flavonols and crown-flavonols as metal cation chelators, The different nature of $\mathrm{Ba} 2+$ and $\mathrm{Mg} 2+$ complexes. Journal of Physical Chemistry A, 102, 5907-5914.

23. Jiang, Y., Wu, Q., \& Chang, X. (2014). A ratiometric fluorescent probe for hydrogen sulfide imaging in living cells. Talanta, 121, 122-126.

24. Murale, D. P., Kim, H., Choi, W. S., \& Churchill, D. G. (2013). Highly selective excited state intramolecular proton transfer (ESIPT)-based superoxide probing. Organic Letters, 15, 3946-3949.

25. Kim, T. I., Kang, H. J., Han, G., Chung, S. J., \& Kim, Y. (2009). A highly selective fluorescent ESIPT probe for the dual specificity phosphatase MKP-6. Chemical Communications, 45, 5895-5897.

26. Das, K., Sarkar, N., Ghosh, A. K., Majumdar, D., Nath, D. N., \& Bhattacharyya, K. (1994). Excited-state intramolecular proton-transfer in 2-(2'-hydroxyphenyl)benzimidazole and 2-(2'-hydroxyphenyl)-benzoxazole-Effect of rotamerism and hydrogen-bonding. Journal of Physical Chemistry, 98, 9126-9132.

27. Mamada, M., Inada, K., Komino, T., Potscavage, W. J., Nakanotani, H., \& Adachi, C. (2017). Highly efficient thermally activated delayed fluorescence from an excited-state intramolecular proton transfer system. ACS Central Science, 3, 769-777.

28. Dick, B., \& Ernsting, N. P. (1987). Excited-state intramolecular proton transfer in 3-hydroxy-flavone isolated in solid argon: Fluorescence and fluorescence-excitation spectra and tautomer fluorescence rise time. Journal of Physical Chemistry, 91, 4261-4265.

29. Iijima, T., Momotake, A., Shinohara, Y., Sato, T., Nishimura, Y., \& Arai, T. (2010). Excited-state intramolecular proton transfer of naphthalene-fused 2-(2'-Hydroxyaryl)benzazole family. Journal of Physical Chemistry A, 114, 1603-1609.

30. Ji, E. K., \& Park, S. Y. (2011). Advanced organic optoelectronic materials: Harnessing excited-state intramolecular proton transfer (ESIPT) process. Advanced Materials, 23, 3615-3642.

31. Chen, Y. P., Yang, Y. F., Zhao, Y., et al. (2019). The effect of different environments on excited-state intramolecular proton transfer in 4'-methoxy-3-hydroxyflavone. Organic Chemistry Frontiers, 6(2), 218-225.

32. Tang, Z., Lu, M. H., Liu, K. J., Zhao, Y. L., Qi, Y. T., Wang, Y., \& Zhang, P. (2018). Solvation effect on the ESIPT mechanism of 2-(4'-amino-2'-hydroxyphenyl)-1H-imidazo-[4,5-c]pyridine. Journal of Photochemistry and Photobiology A: Chemistry, 367, 261-269.

33. Zhao, J. F., Dong, H., \& Zheng, Y. J. (2018). Theoretical insights into the excited state double proton transfer mechanism of deep red pigment alkannin. Journal of Physical Chemistry A, 122, 1200-1208.

34. Hanson, K., Patel, N., Whited, M. T., Djurovich, P. I., \& Thompson, M. E. (2011). Substituted 1, 3-bis (imino) isoindole diols: A new class of proton transfer dyes. Organic Letters, 13, 1598-1601.

35. Driscoll, E., Sorenson, S., \& Dawlaty, J. M. Ultrafast intramolecular electron and proton transfer in bis(imino)isoindole derivatives. Journal of Physical Chemistry A. https://doi.org/10.1021/acs.jpca. 5 b02889.

36. Tao, Y. P., Han, L. G., Han, Y. X., \& Liu, Z. J. (2015). Apoptosis of acute myeloid leukemia HL-60 cells induced by CDK inhibitor SNS-032 and its molecular mechanisms. Spectrochimica Acta, Part A: Molecular and Biomolecular Spectroscopy, 137, 892-898. 
37. Frisch, M. J., Trucks, G. W., Schlegel, H. B., Scuseria, G. E., Robb, M. A., et al. (2016). Gaussian 16, Revision A. 03. Wallingford CT: Gaussian Inc.

38. Cancès, E., Mennucci, B., \& Tomasi, J. (1997). A new integral equation formalism for the polarizable continuum model: Theoretical background and applications to isotropic and anisotropic dielectrics. The Journal of Chemical Physics, 107, 3032-3041.

39. Mennucci, B., Cancès, E., \& Tomasi, J. (1997). Evaluation of solvent effects in isotropic and anisotropic dielectrics and in ionic solutions with a unified integral equation method: theoretical bases, computational implementation, and numerical applications. The Journal of Physical Chemistry B, 101, 10506-10517.

40. Becke, A. D. (1988). Density-functional exchange-energy approximation with correct asymptotic behavior. Physical Review A, 38, 3098-3100.

41. Miehlich, B., Savin, A., Stoll, H., \& Preuss, H. (1988). Results obtained with the correlation-energy density functionals of becke and lee, yang and parr. Chemical Physics Letters, 157, 200-206.

42. Schafer, A., Horn, H., \& Ahlrichs, R. (1992). Ahlrichs, Fully optimized contracted Gaussian basis sets for atoms Li to Kr. The Journal of Chemical Physics, 97, 2571-2577.

43. Schafer, A., Huber, C., \& Ahlrichs, R. (1994). Fully optimized contracted Gaussian basis sets of triple zeta valence quality for atoms Li to Kr. The Journal of Chemical Physics, 100, 5829-5835.

44. Lu, T., \& Chen, F. W. (2012). Multiwfn: A multifunctional wavefunction analyzer. Journal of Computational Chemistry, 33, 580-592.

45. Johnson, E. R., Keinan, S., Sanchez, P. M., Garcia, J. C., Cohen, A. J., \& Yang, W. T. (2010). Revealing noncovalent interactions. Journal of the American Chemical Society, 132, 6498-6506.

46. Zhao, G. J. (2008). Photoinduced intramolecular charge transfer and S2fluorescence in thiophene- $\pi$-conjugated donor-acceptor systems: Experimental and TDDFT studies. Chemistry-A European Journal, 14, 6935-6947.

47. Ding, S., Xu, A. X., Sun, A. K., Xia, Y., \& Liu, Y. J. (2020). An Excited State intramolecular proton transfer-based fluorescent probe with a large stokes shift for the turn-on detection of cysteine: a detailed theoretical exploration. ACS Omega, 5(31), 19695-19701.

48. Su, Y., \& Chai, S. (2014). A TDDFT study of the excited-state intramolecular proton transfer of 1,3-bis(2-pyridylimino)-4,7-dihydroxyisoindole. Journal of Photochemistry and Photobiology A: Chemistry, 290, 109-115.

49. Yang, Y., Liu, Y., Yang, D., Li, H., Jiang, K., \& Sun, J. (2015). Photoinduced excited state intramolecular proton transfer and spectral behaviors of aloesaponarin 1. Spectrochimica Acta, Part A: Molecular and Biomolecular Spectroscopy, 151, 814-820.

50. Fleming, I. (1976). Frontier orbitals and organic chemical reactions. John Wiley and Sons.

51. Liu, Y., Zhao, J. F., Wang, Y., Tian, J., \& Wang, H. Y. (2017). Theoretical study of excited state intramolecular proton transfer (ESIPT) mechanism for a fluorophore in the polar and nonpolar solvents. Journal of Molecular Liquids, 223, 303-309.

52. Zhou, M., Zhao, J., Cui, Y., Wang, Q., Dai, Y., Song, P., \& Xia, L. (2015). Theoretical study on the excited-state intramolecular proton-transfer reaction of 10-hydroxybenzo[h]quinolone in methanol and cyclohexane. Journal of Luminescence, 161, 1-6. 